\title{
A gastrointestinal rotavirus infection mouse model for immune modulation studies
}

\author{
Karen Knipping ${ }^{1,5^{*}}$, Monica M McNeal ${ }^{2}$, Annelies Crienen ${ }^{3}$, Geert van Amerongen ${ }^{4}$, Johan Garssen ${ }^{1,5}$, \\ Belinda van't Land ${ }^{1,5}$
}

\begin{abstract}
Background: Rotaviruses are the single most important cause of severe diarrhea in young children worldwide. The current study was conducted to assess whether colostrum containing rotavirus-specific antibodies (Gastrogard- $R^{\circledR}$ ) could protect against rotavirus infection. In addition, this illness model was used to study modulatory effects of intervention on several immune parameters after re-infection.
\end{abstract}

Methods: BALB/C mice were treated by gavage once daily with Gastrogard- $R^{\circledR}$ from the age of 4 to 10 days, and were inoculated with rhesus rotavirus (RRV) at 7 days of age. A secondary inoculation with epizootic-diarrhea infant-mouse (EDIM) virus was administered at 17 days of age. Disease symptoms were scored daily and viral shedding was measured in fecal samples during the post-inoculation periods. Rotavirus-specific lgM, IgG and IgG subclasses in serum, T cell proliferation and rotavirus-specific delayed-type hypersensitivity (DTH) responses were also measured.

Results: Primary inoculation with RRV induced a mild but consistent level of diarrhea during 3-4 days postinoculation. All mice receiving Gastrogard- $R^{\circledR}$ were $100 \%$ protected against rotavirus-induced diarrhea. Mice receiving both RRV and EDIM inoculation had a lower faecal-viral load following EDIM inoculation then mice receiving EDIM alone or Gastrogard- $R^{\circledR}$. Mice receiving Gastrogard- $R^{\circledR}$ however displayed an enhanced rotavirusspecific T-cell proliferation whereas rotavirus-specific antibody subtypes were not affected.

Conclusions: Preventing RRV-induced diarrhea by Gastrogard- $R^{\circledR}$ early in life showed a diminished protection against EDIM re-infection, but a rotavirus-specific immune response was developed including both $\mathrm{B}$ cell and $T$ cell responses. In general, this intervention model can be used for studying clinical symptoms as well as the immune responses required for protection against viral re-infection.

\section{Background}

Rotavirus is one of the leading causes of severe dehydrating diarrhea in children under the age of five and causes the deaths of $>600,000$ children annually [1]. Rotaviruses, belonging to a genus of double-stranded RNA viruses in the family Reoviridae, infect the mature villus epithelial cells of the small intestine, often leading to fever, vomiting, and diarrhea in children. Current treatment is non-specific and consists mainly of oral rehydration therapy to prevent dehydration. Two liveattenuated vaccines have been licensed recently and have so far proven safe and efficacious [1]. However,

\footnotetext{
* Correspondence: karen.knipping@danone.com

'Danone Research Centre for Specialised Nutrition, P.O. Box 7005, 6700 CA Wageningen, The Netherlands

Full list of author information is available at the end of the article
}

previous experience with the first licensed rotavirus vaccine, which was withdrawn from the market a year after introduction due to a possible correlation between vaccine application and the occurrence of intussusceptions [2], has reinforced the need to develop alternative approaches to control rotavirus disease. Fundamental to this development is a better insight of the immune responses related to gastrointestinal virus infections which will help to develop improved treatment and/or preventive regimes.

Mice provide a reliable animal model for studying the immune responses during a primary rotavirus infection, although the kinetics of rotavirus infections in mice differs slightly from what is observed in humans [3]. Unlike infant mice which are susceptible to symptomatic infection with rotavirus only during the first 15 days of

\section{Biomed Central}


life, human infants can suffer from multiple rotavirus infections up to the age of five years. There are even many reports of adult rotavirus infection, particularly in the elderly [4]. Aside from these differences, studies of rotavirus infection in mice can provide valuable information on the induction of immune responses by the virus. Sheridan et al. was one of the first to describe a mouse model studying rotavirus-specific immunity. Their findings indicate that (i) infection occurs in all age groups but diarrheal disease is observed in neonatal animals only and that (ii) re-infection of adult animals is associated with suppression of virus-specific cellmediated immunity [5].

Despite many years of research, the immune correlates of protection from rotavirus infection and disease are still not completely understood. The mouse model has been extensively used to investigate the contribution of different components of the immune system necessary for protection. These studies have suggested that both humoral- and cell-mediated immunity are important in the resolution of ongoing rotavirus infection and in protection against subsequent re-infection [6]. In more detail, studies have shown that B cells were essential for long-term protection against rotavirus [7]. $\mathrm{CD} 4^{+} \mathrm{T}$ cells were pivotal for the development of approximately $90 \%$ of the rotavirus-specific intestinal IgA. Their presence seems to be critical for the establishment of protective long-term memory responses and IgA antibody in serum and stool samples correlates best with protection against re-infection $[8,9]$. $\mathrm{CD}^{+} \mathrm{T}$ cells appeared to be involved in providing partial protection against re-infection $[10,11]$.

The original neonatal mouse model has been developed in order to determine the effects of an immature immune system on responses to candidate vaccines [12]. In the present study, this model has been modified to a sensitive gastrointestinal viral infection and illness model in infant mice for testing nutritional compounds for their antiviral and/or immunomodulatory activity. Therefore, neonatal mice were inoculated with a rhesus rotavirus strain (RRV) at an early age for immune induction and later challenged with epizootic-diarrhea infant-mouse (EDIM) virus. Protection due to intervention with the nutritional supplement Gastrogard- $\mathrm{R}^{\circledR}$ was determined by reduction of diarrhea and protection against later EDIM challenge, measured by rotavirus fecal-shedding. Associations between protection and both humoral (antibody) and cellular ( $\mathrm{T}$ cell) responses were examined.

Gastrogard- $R^{\circledR}$ is prepared from the colostrum of hyperimmunised cows and contains high antibody titers against four human rotavirus serotypes, as measured in a virus neutralisation test [13]. It is used as prophylactic treatment of 'at risk' children aged one month to three years to prevent diarrhea due to rotavirus infection and the efficacy of treatment was established in a clinical trial in children aged 3 to 15 months [13].

The purpose of this study was to demonstrate a modified gastro-intestinal viral re-infection model for studying the effects of nutritional intervention on clinical symptoms as well as the development of immune responses and protection against subsequent viral infection.

\section{Methods \\ Viruses}

To obtain a large quantity of virulent epizootic-diarrhea infant-mouse virus (EDIM), 78 neonatal mice were inoculated at the age of 4 days with $5 \mu$ EDIM $7.8^{*} 10^{7}$ focus forming units $/ \mathrm{ml}$, a kind gift from Dr. Richard Ward, Cincinnati Children's Hospital Medical Center, USA. Stool samples were collected and pooled from day 5 until day 13 and EDIM was extracted with genetron (1,1,2-trichloro-1,2,2,-trifluoroethane, Sigma-Aldrich, Zwijndrecht, The Netherlands). The stool preparation of EDIM contained $400 \mu \mathrm{g}$ rotavirus $/ \mathrm{ml}$ as determined in the IDEIA ELISA (Dako diagnostics, Glostrup, Denmark) verified against a rotavirus stock with known concentration of rotavirus. To determine whether EDIM caused diarrheal disease when orally administered to neonatal mice, 7 mice were inoculated with $5 \mu$ l EDIM ( $400 \mu \mathrm{g}$ rotavirus $/ \mathrm{ml}$ ) at the age of 7 days. At day 2 p.i., $70 \%$ of the mice were suffering from diarrhea, rising to $100 \%$ at day 5 and declining again from day 6 .

The rhesus rotavirus (RRV) strain used in this study, also provided by Dr. Richard Ward, was grown in African green monkey kidney MA104 cells (ECACC, Salisbury, UK) and concentrated by ultracentrifugation. The titer was determined using a titration assay in MA104 cells resulting in a $50 \%$ cell culture infective dose $\left(\mathrm{CCID}_{50}\right)$ of $1 \times 10^{7.7}$. Virus stocks were UV-inactivated overnight at short wave UV $254 \mathrm{~nm}$ (UV cabinet CM10; Alltech, Breda, The Netherlands) and used for measuring delayed-type hypersensitivity (DTH) responses and $\mathrm{T}$ cell stimulation. Inactivation of rotavirus was confirmed using the titration assay in MA104 cells. For DTH responses, the EDIM and RRV stocks were diluted $100 \times$ in PBS. For use in T cell stimulation experiments, caesium chloride gradient purified EDIM double layered particles (provided by Dr. Richard Ward) were diluted to $1 \mu \mathrm{g} / \mathrm{ml}$ and RRV was diluted to a $\mathrm{CCID}_{50}$ of $5 \times 10^{7}$.

Simian rotavirus, SA-11, (ATCC, Middlesex, UK) was grown in MA104 cells and concentrated by ultracentrifugation. SA-11 contained $14 \mu \mathrm{g}$ rotavirus $/ \mathrm{ml}$ as determined in the IDEIA ELISA, verified against a rotavirus stock with known concentration of rotavirus. For the determination of rotavirus-specific antibodies in serum a concentration of $500 \mathrm{ng} / \mathrm{ml} \mathrm{SA-11}$ was used. 


\section{Mice}

Pregnant female BALB/c mice were housed individually in sterile micro-isolation cages under standard housing conditions at the animal facility of the Dutch Vaccine Institute with a $12 \mathrm{~h}$ dark and light cycle. Animal care and use were performed in accordance with the guidelines of the Dutch Committee of Animal Experiments. Weaning of suckling pups occurred at 21 days of age. Alternatively, pups immunized and challenged prior to weaning remained with their dams.

\section{Study design}

A total of 91 neonatal mice were cross-fostered and divided into 4 study groups as depicted in Table 1 . A schematic design of the mouse model is shown in Figure 1. From day 4 until day 10 of age, pups of group D received daily $20 \mu \mathrm{l}$ PBS containing rotavirus-specific antibodies, Gastrogard- ${ }^{\circledR}$, (kindly provided by Dr. Rosie Pereira) (1 mg/day) by oral gavage. At day 7 of age, pups of group A, C and D were inoculated by oral gavage with $10 \mu \mathrm{l}$ RRV $\left(\mathrm{CCID}_{50} 1 \times 10^{7.7}\right)$ and mice of group B were inoculated with $10 \mu \mathrm{l}$ PBS as a control. From day 8 until day 14, diarrhea and severity of illness was scored. From day 8 until day 27 feces were collected daily, the feces of all animals within one group were pooled each day. At day 16 of age, a blood sample was taken and pooled from all animals within one group. At day 17 of age, pups of group B, C and D were inoculated with $5 \mu \mathrm{l}$ EDIM (400 $\mu \mathrm{g}$ rotavirus/ml) and mice of group A were inoculated with $10 \mu \mathrm{l}$ PBS as a control. At day 27 of age a rotavirus-specific DTH was elicited by subcutaneous inoculation of UV-inactivated rotavirus in the ear pinnea, EDIM $(1 \mu \mathrm{g} / \mathrm{ml})$ in the left ear and RRV $\left(\mathrm{CCID}_{50} 5 \times 10^{7}\right)$ in the right ear. Non-inoculated mice of comparable age were also injected as a control. Twenty four hours later, the DTH responses were determined by measuring ear thickness using a digital micrometer (Mitutoyo, Veenendaal, The Netherlands) prior to collection of individual spleen and individual blood samples.

\section{Diarrhea and severity of illness scoring}

Daily evaluation, starting 1 day after RRV inoculation, for the presence of diarrhea (defined as having diarrheal stool after gentle palpation of the abdomen) was performed for each animal, and results were reported as the percent of animals having diarrhea in each group. Stool samples were collected daily, the feces of all animals within one group were pooled each day. The severity of illness was scored daily by assigning numeric values to the color of stool where a high score indicates severe illness (yellow $=3$; yellow-brown $=2$; brown $=$ 1 ), degree of soiling (very soiled $=4$; somewhat soiled = 1 ; no soiling $=0$ ), and consistency (very liquid $=4$; liquid $=3$; solid $=1$ ) of the stool. The severity score was calculated by dividing the total severity score by the total number of animals on each day after RRV immunization [12].

\section{Detection of rotavirus in feces}

A commercial ELISA kit (IDEIA; Dako diagnostics) for the detection of group A rotavirus in human fecal samples was used according to the manufacturer's protocol. In short, precoated wells with rotavirus-specific polyclonal antibody were sampled with a reference EDIM stock with known concentration $(300 \mathrm{ng} / \mathrm{ml})$ which was used as a standard, stool samples (dilutions $5 \times, 10 \times, 50 \times$ and $100 \times$ ), positive and negative control supplied in the kit. Then $100 \mu$ l rotavirus-specific polyclonal antibody-peroxidase labeled was added and incubated for 1 hour at RT. Wells were washed with $350 \mu$ l wash buffer and incubated with $100 \mu \mathrm{l}$ of TMB substrate for $10 \mathrm{~min}$. at room temperature (RT). The reaction was stopped by adding $100 \mu \mathrm{l}$ of $0.46 \mathrm{~mol} / \mathrm{L}$ sulfuric acid and the absorbance was measured at $450 \mathrm{~nm}$ on a microplate reader (BioRad, Hemel Hempstead, UK). The ELISA cutoff was the mean absorbance of the negative control at $450 \mathrm{~nm}$ plus a factor of 0.1 . The absorbance of the positive control should be in the range indicated at the validation inlay in the kit. Concentration of rotavirus in the samples was expressed in $\mathrm{ng} / \mathrm{ml}$.

In vitro Concanavalin $\mathrm{A}$ and rotavirus-specific proliferation of spleen cells

Spleen cells of individual mice of group A $(n=22)$, group $B(n=23)$, group $C(=24)$, group $D(n=22)$ and a control group of non-inoculated mice $(n=15)$ were isolated by using a cell strainer $40 \mu \mathrm{m}$ (BD Falcon,

Table 1 Study design of inoculation of mice with RRV and/or EDIM and intervention

\begin{tabular}{lcccc}
\hline Group & $\mathbf{n}$ (pups) & RRV at day $\mathbf{7}$ of age & EDIM at day $\mathbf{1 7}$ of age & Intervention at day $4-10$ of age \\
\hline Group A & 22 & $x$ & - & - \\
Group B & 23 & - & $x$ & - \\
Group C & 24 & $x$ & $x$ & - \\
Group D & 22 & $x$ & $x$ & Gastrogard-R $^{\circledR}$ \\
\hline
\end{tabular}

Group A received RRV only, group B received EDIM only as controls. Groups C and D received both RRV and EDIM. Group D received daily $20 \mu \mathrm{I}$ PBS containing rotavirus-specific antibodies (Gastrogard- $\left.R^{\mathbb{R}}\right) 1 \mathrm{mg} /$ day. 


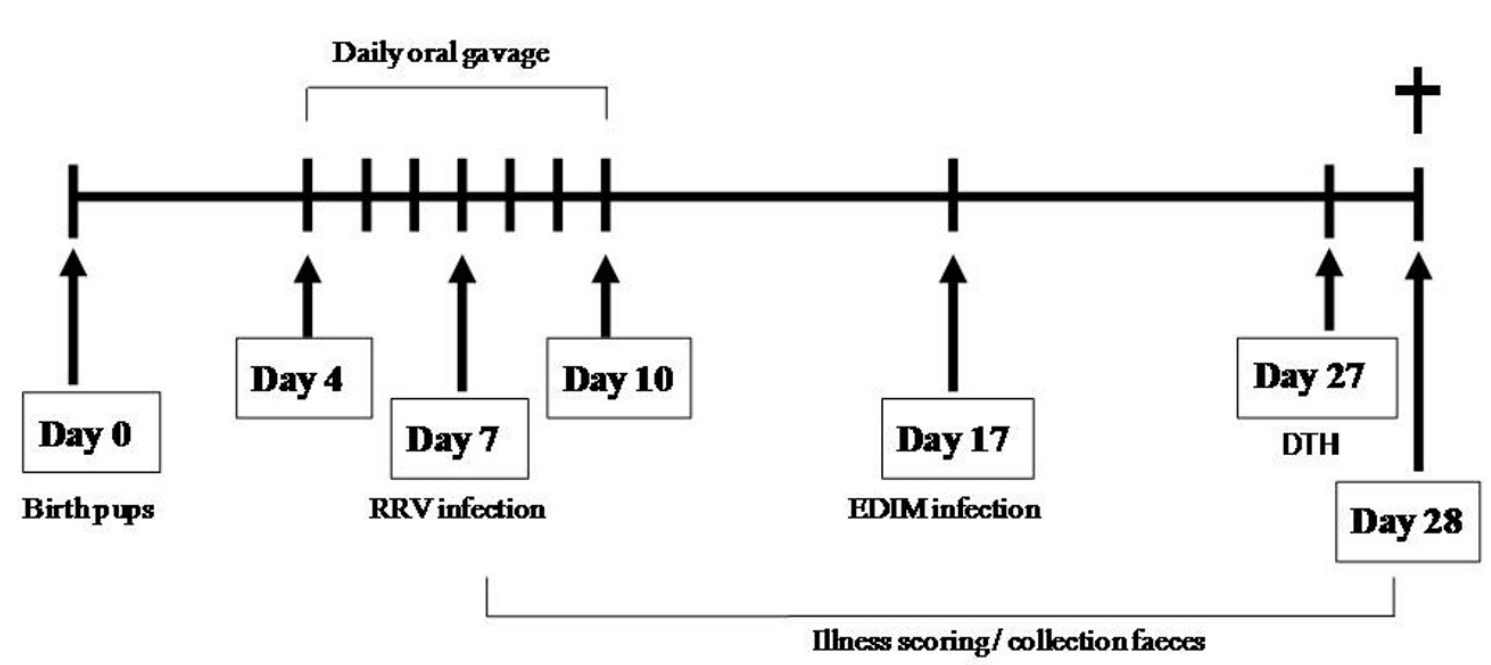

Figure 1 Schematic design of the rotavirus double infection model. At day 0 the pups were born. From day 4 until day 10 after birth pups one group received intervention of rotavirus-specific antibodies (Gastrogard- $R^{\circledR}$ ) by oral gavage. At day 7 of age pups were inoculated with RRV by oral gavage. From day 8 on, the number of pups experiencing illness and the severity of illness was scored daily. From day 8 until the end of the experiment, feces were collected. At day 16 a blood sample was collected and at day 17 of age pups were inoculated with EDIM by oral gavage. At day 27 of age a rotavirus-specific DTH was elicited by subcutaneous inoculation of rotavirus in the ear pinnea, EDIM in the left ear and RRV in the right ear. DTH responses were measured 24 hours later, prior to collection of spleen and blood samples.

Breda, The Netherlands) to a single-cell suspension. The cells were incubated with $5 \mathrm{ml}$ ice-cold lysis buffer $(4.15$ g ammonium chloride (Merck, Haarlem, The Netherlands) + 0.5 g potassium bicarbonate (Sigma-Aldrich, Zwijdrecht, The Netherlands) + 18.6 mg EDTA (SigmaAldrich) in $500 \mathrm{ml}$ water, $\mathrm{pH} \mathrm{7.3)}$ and incubated for 5 minutes on ice for lysing red blood cells. After incubation, $10 \mathrm{ml}$ of ice-cold culture medium, RPMI-1640 (Life Technologies, Breda, The Netherlands) + heat inactivated 10\% FBS (Perbio Science, Etten-Leur, The Netherlands) + penicillin $50 \mathrm{U} / \mathrm{ml}$ and streptomycin 50 $\mu \mathrm{g} / \mathrm{ml}$ (Life Technologies) $+1 \%$ sodium pyruvate (Life Technologies) was added. The cell suspension was centrifuged for $5 \mathrm{~min}$. at $400 \times \mathrm{g}$ and $4^{\circ} \mathrm{C}$ (Sorvall RT7, Thermo Fisher Scientific, Breda, The Netherlands) and resuspended in $2 \mathrm{ml}$ ice-cold culture medium. For the Con A type IV (Sigma-Aldrich) stimulation, $2 \times 10^{5}$ cells were stimulated with $3 \mu \mathrm{g} / \mathrm{ml}$ Con A. For the rotavirus-specific stimulation, $1 \times 10^{6}$ cells were stimulated with $5 \times 10^{7} \mathrm{CCID}_{50} \mathrm{UV}$-inactivated RRV or $1 \mu \mathrm{g} / \mathrm{ml}$ UV-inactivated EDIM dl particles. Plates were incubated at $37^{\circ} \mathrm{C}$ and $5 \% \mathrm{CO}_{2}$. Con A proliferated cells were pulsed after 24 hours and the rotavirus-specific proliferated cells after 5 days with $0.4 \mu \mathrm{Ci} /$ well tritium-thymidine (PerkinElmer, Groningen, The Netherlands) and incubated overnight. Cells were harvested on filter plates (Unifilter GF-C; PerkinElmer) and radioactivity was determined in $25 \mu \mathrm{l}$ of scintillation cocktail (Ultima gold; PerkinElmer) in a Wallac MicroBeta liquid scintillation detector (PerkinElmer). Stimulation index was calculated as the ratio of counts per minute for antigenstimulated cultures to background cultures.

Detection of serum rotavirus-specific IgM, IgG and IgGsubclass antibodies

Serum samples were collected from mice bled from the orbital sinus and centrifuged 10 minutes at $400 \times \mathrm{g}$ (Sorvall RT7; Thermo Fisher Scientific). Wells of a 96-well plate (BD Falcon, Breda, The Netherlands) were coated overnight with $100 \mu \mathrm{l} 500 \mathrm{ng} /$ well of simian rotavirus (SA11) at $4^{\circ} \mathrm{C}$. As described previously, SA-11 is an efficient EDIM antigen substitute in an ELISA [5]. Wells were washed $4 \times$ with $200 \mu$ l PBS (Life Technologies) $+0.05 \%$ Tween 20 (Merck) and blocked for $30 \mathrm{~min}$. at $37^{\circ} \mathrm{C}$ with $200 \mu \mathrm{l}$ assay buffer (PBS $+0.5 \%$ BSA (MP Biomedicals, Eindhoven, The Netherlands) $+0.05 \%$ Tween 20). As reference serum, the sera from pups and mothers from a previous EDIM passage experiment that was shown to contain antibodies to rotavirus were used. For each isotype or subclass, a different reference serum with the highest titer, tested in a serial dilution series starting from a 1:10 dilution, was selected and set to the arbitrary unit (AU) of 100. At day 16, individual serum samples were collected and then pooled per group. At day 28 individual serum samples were collected and were tested individually. Serial dilutions in $100 \mu \mathrm{l}$ were made of the reference serum and individual serum samples, starting from a 1:10 dilution in assay buffer. Wells were washed as described above and incubated for 1 hour at $37^{\circ} \mathrm{C}$ with $100 \mu \mathrm{l}$ 1:7,500 goat antimouse IgM $\mu$-chain-HRP (Sigma-Aldrich) or 1:1,000 goat 
anti-mouse IgG-HRP (Tebu-Bio, Heerhugowaard, The Netherlands) or 1:5,000 goat anti-mouse IgG1-HRP (AbD Serotec, Düsseldorf, Germany) or 1:1,000 goat anti-mouse IgG2a-HRP (AbD Serotec) or 1:1,000 goat anti-mouse IgG2b-HRP (AbD Serotec) or 1:1,000 goat anti-mouse IgG3-HRP (AbD Serotec) in assay buffer. Plates were washed, $100 \mu \mathrm{l}$ 3,3',5,5'-tetramethylbenzidine (TMB; Perbio Science) was added and incubated for $10 \mathrm{~min}$ at room temperature. The reaction was stopped with $100 \mu \mathrm{l} 10 \%$ sulphuric acid (Merck) and the absorbance measured at $450 \mathrm{~nm}$ on a microplate reader (BioRad). Results were calculated against the reference serum and expressed in AU. Limit of detection: 0.15 AU for IgG and IgM, 2.5 AU for IgG1, 0.6 AU for IgG2a, 0.15 AU for IgG2b and 0.3 AU for IgG3.

\section{Statistical analysis}

Power calculation indicated a group size of at least 13 animals to find significant differences in diarrheal score (detectable difference in diarrheal score $=20 \%$, expected $\mathrm{CV}=15 \%, \alpha=0.05, \beta=0.20$ ). All statistical analyses were performed using the statistical software package GraphPad Prism, version 4.03. A two-sample t test was used when two groups were compared. Values of P less than 0.05 were considered significant.

\section{Results}

Diarrhea and severity of illness score of RRV infected pups Diarrhea and severity of illness was monitored daily during the first RRV infection from day 8 ( 1 day p.i.) until day 14 of age. Diarrhea in mice inoculated with RRV (group A and C combined) appeared at day 9 with 63\% of the pups having symptoms of diarrhea, rising to a maximum of $70 \%$ at day 10 and declining to zero at day 13 (Figure 2A). When the mice were supplemented with rotavirus-specific antibodies (Gastrogard- $R^{\circledR}$ ) orally (group D) prior and during the RRV infection, no signs of diarrhea occurred indicating a complete protection against RRV induced diarrhea.

The severity of illness score, as depicted in Figure 2B, was monitored daily by assigning numeric values to the color of stool. A high score indicates severe illness, minimum score is $2(18.2 \%)$ and maximum score is 11 (100\%). Illness in mice inoculated with RRV (group A and $\mathrm{C}$ combined) appeared at day 9 with an average severity score of $38.6 \%$, reaching a maximum of $52.3 \%$ at day 10 and declining after day 11 . Mice supplemented with Gastrogard- $\mathrm{R}^{\circledR}$ orally prior and during the RRV infection showed no signs of illness.

\section{Viral shedding of RRV in feces}

Viral shedding in the feces was detected by measuring the amount of virus antigen shed after the RRV inoculation at day 7. Rotavirus in the feces after RRV inoculation was detectable but in low levels (between $15-130 \mathrm{ng} / \mathrm{ml}$ ) during RRV infection (group A and C), but no rotavirus was detected in the Gastrogard- $R^{\circledR}$ group (group D) (data not shown).

\section{Viral shedding of EDIM in feces}

Viral shedding in the feces was detected by measuring the amount of virus antigen shed after the EDIM inoculation at day 17 . The results of the viral shedding after the EDIM inoculation are depicted in Figure 3. A primary infection with RRV decreased viral shedding by $81 \%$ during a secondary infection with EDIM (Figure 3B) compared to infection with EDIM alone (Figure 3A). Similar findings have previously been described with heterologous rotavirus infection in mice $[8,12]$. Intervention with Gastrogard- $\mathrm{R}^{\circledR}$ had $100 \%$ protected the mice against RRV induced diarrhea, but viral shedding during the secondary infection with EDIM showed no significant difference compared to the EDIM alone group (Figure 3C). However, in the EDIM group, shedding of rotavirus was measured up until day 27 , whereas in the Gastrogard- $R^{\circledR}$ group, no rotavirus was detected in the feces after day 24 . This might indicate that passive protection against a primary illness does not protect against viral shedding during a secondary infection, though clearing of rotavirus seemed more rapid in the Gastrogard- $\mathrm{R}^{\circledR}$ group than in mice inoculated with EDIM alone.

\section{Delayed-type hypersensitivity (DTH) reaction to rotavirus EDIM and RRV}

To analyze RRV- and EDIM-specific cell-mediated immunity of all study groups, a DTH response was measured by subcutaneous injection of rotavirus in the ear pinnea, RRV $\mathrm{CCID}_{50}$ of $2.5 \times 10^{7}$ in the right ear and EDIM $4 \mu \mathrm{g} / \mathrm{ml}$ in the left ear (Figure 4). As a control, the same rotaviruses were also administered to non-inoculated mice $(n=15)$ of the same age. There was little measurable swelling compared to the control with RRV (data not shown). It has been shown previously that a rotavirus-specific DTH response was not elicited when neonatal mice were infected at any time point after primary infection [5]. EDIM induced a small but significant $(\mathrm{p}=0.01)$ increase in ear swelling in the EDIM group (group B) compared to the control, indicating the induction of specific cellular immunity. The RRV (group A), RRV+EDIM (group C) and Gastrogard- $R^{\circledR}$ (group D) groups were all comparable to the control. This might indicate that mice who received a primary infection at a young age show a DTH suppression when re-infected at an older age.

\section{In vitro Concanavalin A and rotavirus-specific proliferation} in spleen cells

To analyze $\mathrm{T}$ cell responses, spleen cells from all study groups were isolated and ex vivo restimulated with 


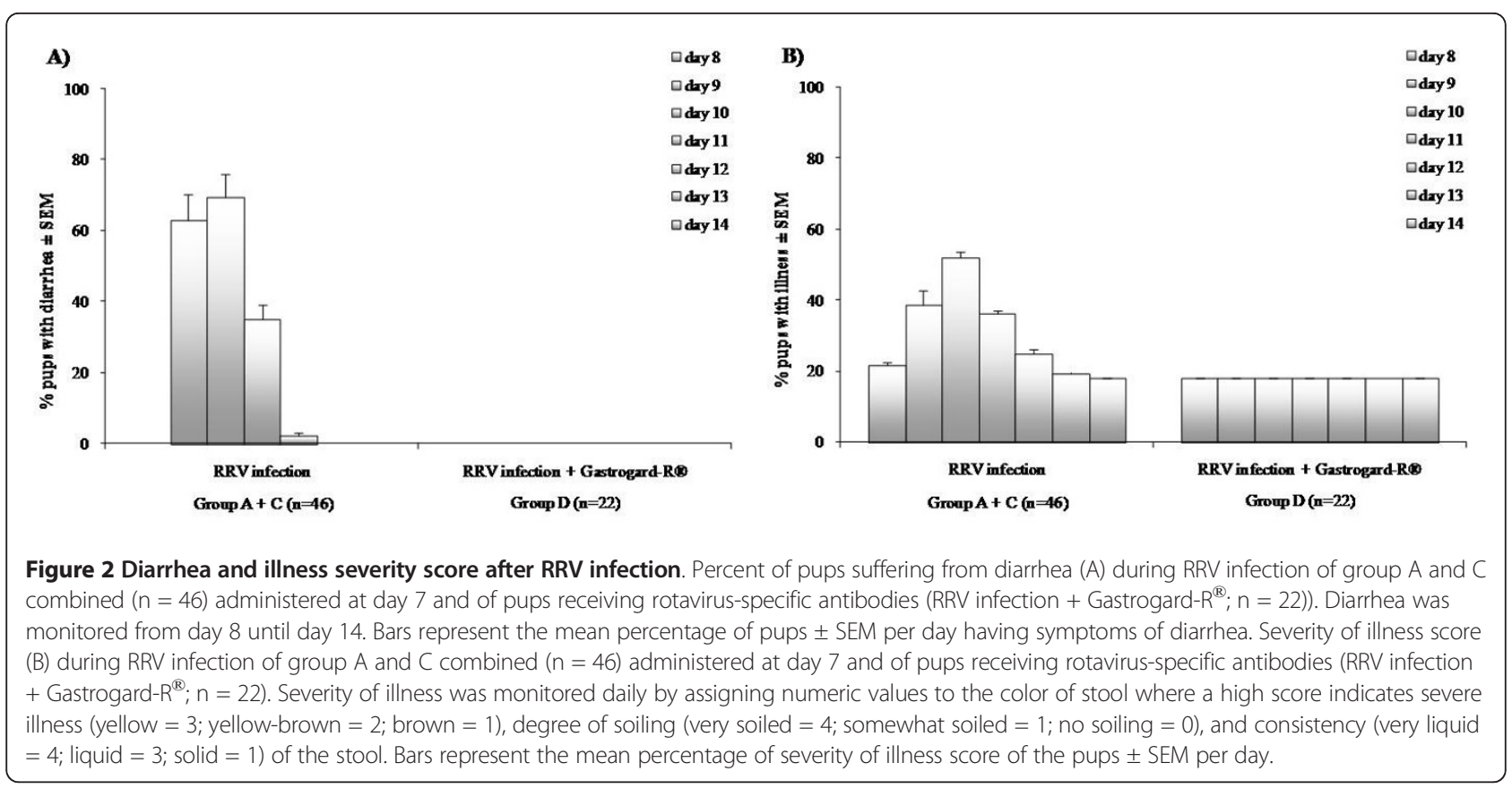

either Concanavalin A (Con A), RRV or EDIM. As a control, spleen cells of non-inoculated mice $(n=15)$ of the same age were used. Con A induced a significant stimulation of $\mathrm{T}$ cell proliferation with an average stimulation index (Con A stimulated cells/non-stimulated cells) of approximately 30 . However, there were no differences seen between the groups (data not shown). Incubation of the spleen cells with EDIM showed no proliferation (data not shown), but RRV incubation induced proliferation of $\mathrm{T}$ cells as shown in Figure 5. The RRV+EDIM

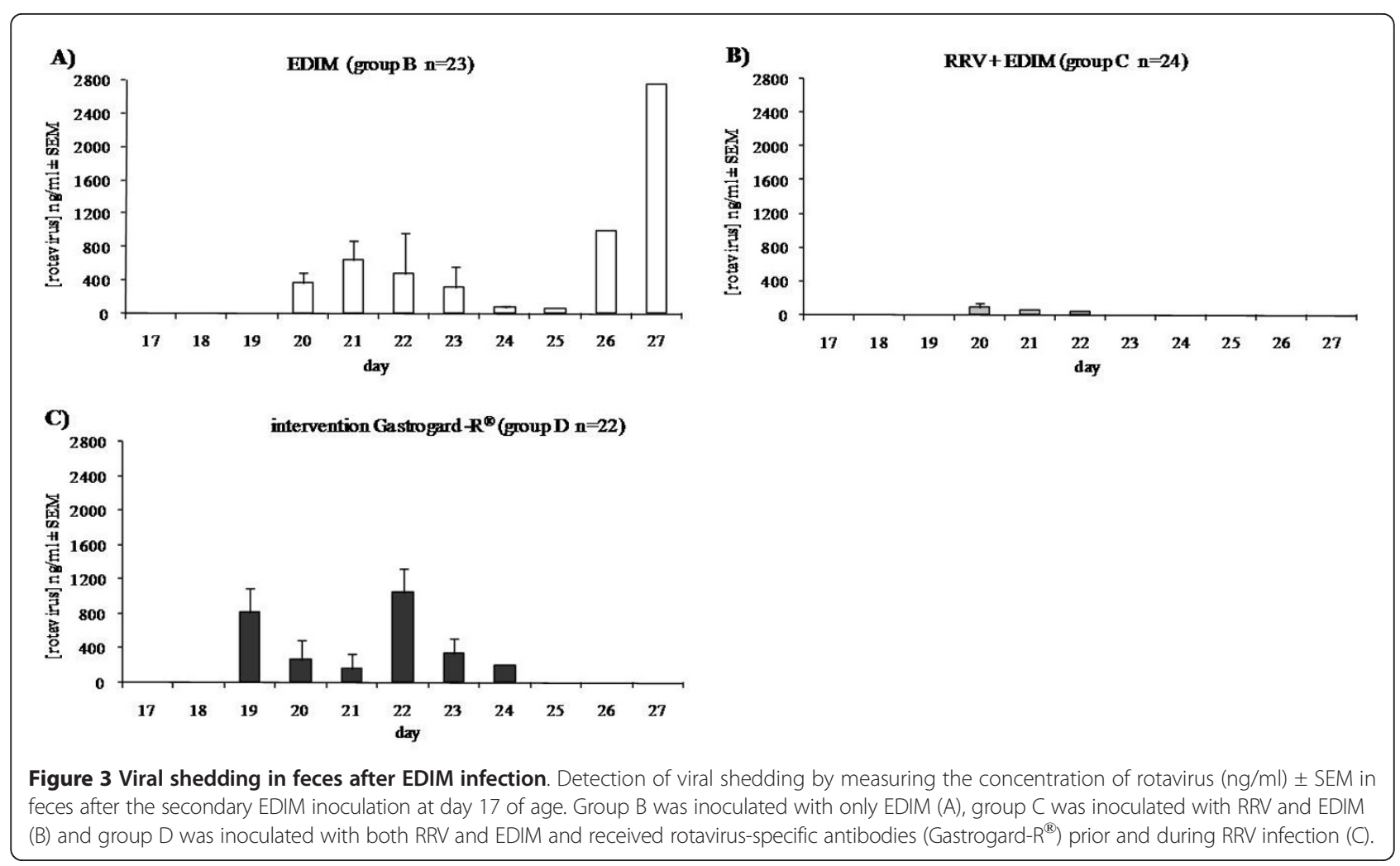




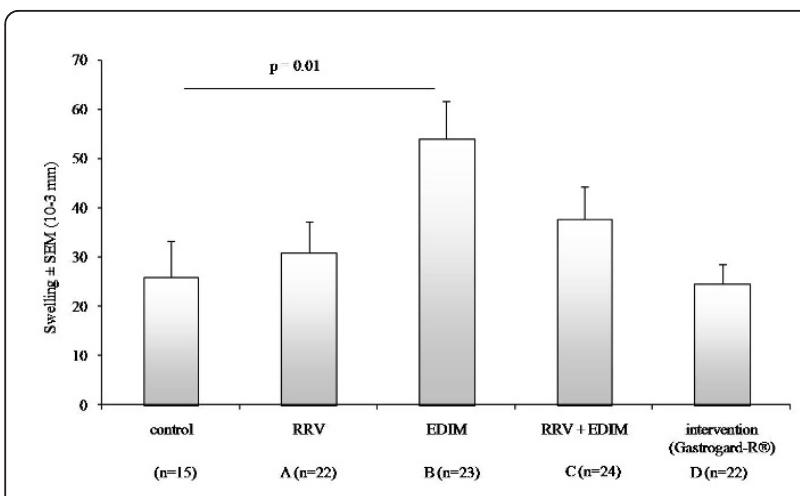

Figure 4 DTH responses to rotavirus. DTH response to EDIM by measuring ear thickness 24 hours after administration of EDIM in the left ear pinnea. Bars represent the mean ear swelling $\left(10^{-3} \mathrm{~mm}\right)$ per group \pm SEM. EDIM induced a significant $(p=0.01)$ increase in ear swelling in the EDIM group compared to the control. The RRV, RRV + EDIM and Gastrogard- ${ }^{\circledR}$ groups were not significantly different from the control.

group (group $C$ ) as well as the Gastrogard- $R^{\circledR}$ group (group D) showed a significant increase in $\mathrm{T}$ cell proliferation ( $\mathrm{p}<0.05$ and $\mathrm{p}<0.0001$ respectively) compared to non-infected mice. These results suggest that multiple infections are needed to acquire a sufficient amount of rotavirus-specific memory $\mathrm{T}$ cells in the spleen to be able to re-stimulate these $\mathrm{T}$ cells in vitro.

\section{Rotavirus-specific serum IgM and IgG antibodies}

Rotavirus-specific IgM and IgG were measured in the serum individually collected at day 16 and then pooled per group (pre-EDIM serum) and in the individual sera

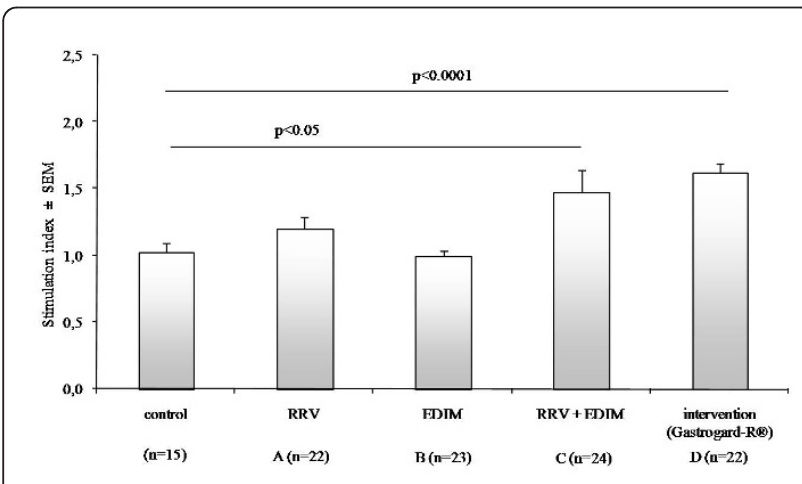

Figure 5 T-cell proliferation by antigen-specific stimulation with rotavirus RRV. Spleen cells of individual mice were isolated at day 28 and $1 \times 10^{6}$ cells were stimulated with $5 \times 10^{7}$ CCID $_{50}$ UVinactivated RRV for 5 days. Proliferation of T cells was determined by measuring incorporation of tritium-thymidine. Bars represents the stimulation index (RRV stimulated cells/non-stimulated cells) \pm SEM per group. The RRV + EDIM group as well as the Gastrogard- $R^{\circledR}$ group showed a significant increase in T cell proliferation $(p<0.05$ and $p<0.0001$ respectively) compared to non-infected mice (control). of the pups collected at day 28 (post-EDIM serum). RRV inoculation at day 7 resulted in rotavirus-specific IgM titers (Figure 6A) in the pre-serum of about 100 $\mathrm{AU}$ in the RRV (group A) and RRV+EDIM (group C) groups. There was no rotavirus-specific IgM detectable in the EDIM group (group B). Surprisingly, even though clinical symptoms during the RRV infection were inhibited by Gastrogard- $\mathrm{R}^{\circledR}$ (group D), a low rotavirus-specific IgM level (10 AU) was measured in this group. In the post EDIM inoculation sera, the rotavirus-specific IgM titers of the RRV and RRV+EDIM groups were not different from the pre-serum, but the rotavirus-specific IgM antibody titer was increased in the EDIM group as well as the Gastrogard- $R^{\circledR}$ group to 90 AU.

The rotavirus-specific IgG titers (Figure 6B) in the pre-serum showed similar results as the rotavirus-specific IgM with titers of about $100 \mathrm{AU}$ in the RRV and RRV+EDIM groups, non-detectable in the EDIM group and low but detectable (20 AU) in the Gastrogard- ${ }^{\circledR}$ group. Inoculation with EDIM increased the titers of rotavirus-specific IgG in all groups (RRV 350 AU; RRV +EDIM 520 AU; EDIM 50 AU; Gastrogard-R ${ }^{\circledR} 125$ AU).

\section{Rotavirus-specific serum IgG subclass antibodies}

The rotavirus-specific IgG subclasses IgG1, IgG2a, IgG2b and IgG3 were measured in the pool serum, individually collected and then pooled per group, at day 16 (pre-EDIM serum) and in the individual sera of the pups collected at day 28 (post-EDIM serum). Like rotavirus-specific IgG titers, the pre-serum showed detectable levels of all subclasses in the RRV and RRV+EDIM groups, 2 times lower in the Gastrogard- $R^{\circledR}$ group and non-detectable in the EDIM group (data not shown). The rotavirus-specific IgG subclass titers in the post-serum were markedly higher and in Figure 7 the geometric mean titers (GMT) per group are shown. Primary rotavirus inoculation at day 7 of age (RRV; group A) showed the following antibody titers; IgG2a antibodies (GMT 838 AU), IgG3 (GMT 213 AU), IgG2b (GMT 164 AU) and IgG1 (GMT 131 AU). A secondary EDIM inoculation at day 17 of age (RRV+EDIM; group C) showed similar IgG2a (GMT 981 AU), IG2b (GMT $151 \mathrm{AU}$ ) and IgG1 (GMT $125 \mathrm{AU}$ ) levels, only the amount of IgG3 seemed to be elevated (GMT 555 AU) but this increase was not significant. Primary inoculation with EDIM at day 17 of age (group B) resulted in low antibody levels for all subclasses (range 1-4 AU). Antibody levels in the mice receiving Gastrogard- $R^{\circledR}$ were significantly lower than the RRV+EDIM group (IgG1 $\mathrm{p}=0.035$, IgG2a $\mathrm{p}=0.024$, IgG2b $\mathrm{p}=0.025$, IgG3 $\mathrm{p}=0.001)$. However, this Gastrogard- $\mathrm{R}^{\circledR}$ group showed significantly higher levels of antibodies than the EDIM group (IgG1 p $=0.028$, IgG2a $\mathrm{p}=0.002$, IgG2b $\mathrm{p}=0.002$, IgG3 $\mathrm{p}=0.007)$. These results indicate that although Gastrogard- $\mathrm{R}^{\circledR}$ had completely inhibited rotavirus-induced diarrhea during a primary 

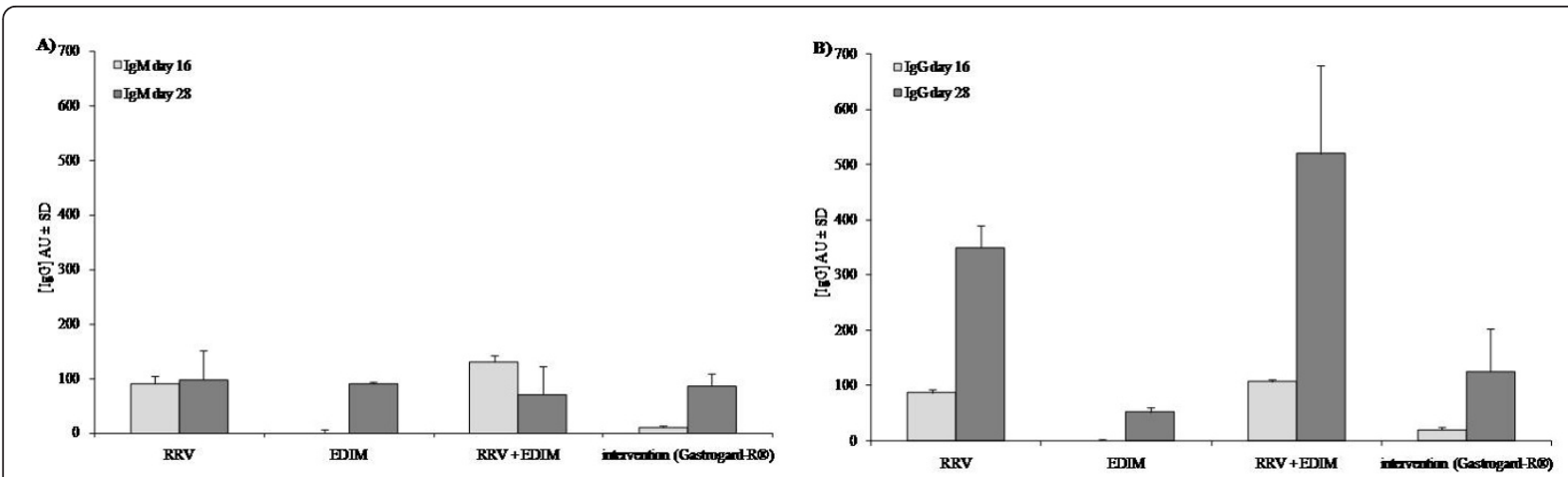

Figure 6 Rotavirus-specific IgM and IgG antibody titers in serum. Rotavirus-specific lgM (A) and lgG (B) antibody titers in arbitrary units (AU) $\pm \mathrm{SD}$ in serum collected at day 16 (pre-EDIM serum) and at day 28 (post-EDIM serum). The serum at day 16 is a pooled serum collected from all animals within a group, at day 28 the sera were collected and tested individually (RRV $n=22$; EDIM $n=23$; RRV+EDIM $n=24$; intervention Gastrogard- $R^{\circledR} n=22$ ) and the mean titers are depicted.

infection, some infection had occurred or stimulation of the immune system because B cells were activated and rotavirus-specific IgG (subclass) antibodies were produced.

\section{Discussion}

In this study a neonatal mouse model, originally developed by VanCott et al. [12], was modified to investigate the effect of nutritional intervention (Gastrogard- $R^{\circledR}$ ) during a primary (heterologous) rotavirus infection and/ or on a secondary (homologous) rotavirus infection. Gastrogard- $\mathrm{R}^{\circledR}$ is prepared from the colostrum of hyperimmunised cows and contains high antibody titers against four human rotavirus serotypes. In parallel, the neonatal mouse model could provide better insight into the immunological response to rotavirus since mechanism of rotavirus protection and rotavirus clearance in mice are still not fully understood. The ability of a neonatal mouse or human to generate sufficient immune effectors needed for protection after gastrointestinal virus infection is dependent on its state of immunological maturity. Specific immune cell functions as well as the gastrointestinal tract mature in neonatal mice through the weaning period, while the numbers of immune cells in inductive and effector sites increase gradually [14]. Many studies have been performed to clarify the immune response to rotavirus infection. Clearance of rotavirus can occur $\mathrm{T}$ cell independent $[15,16]$ as well as B cell/antibody independent $[17,18]$.

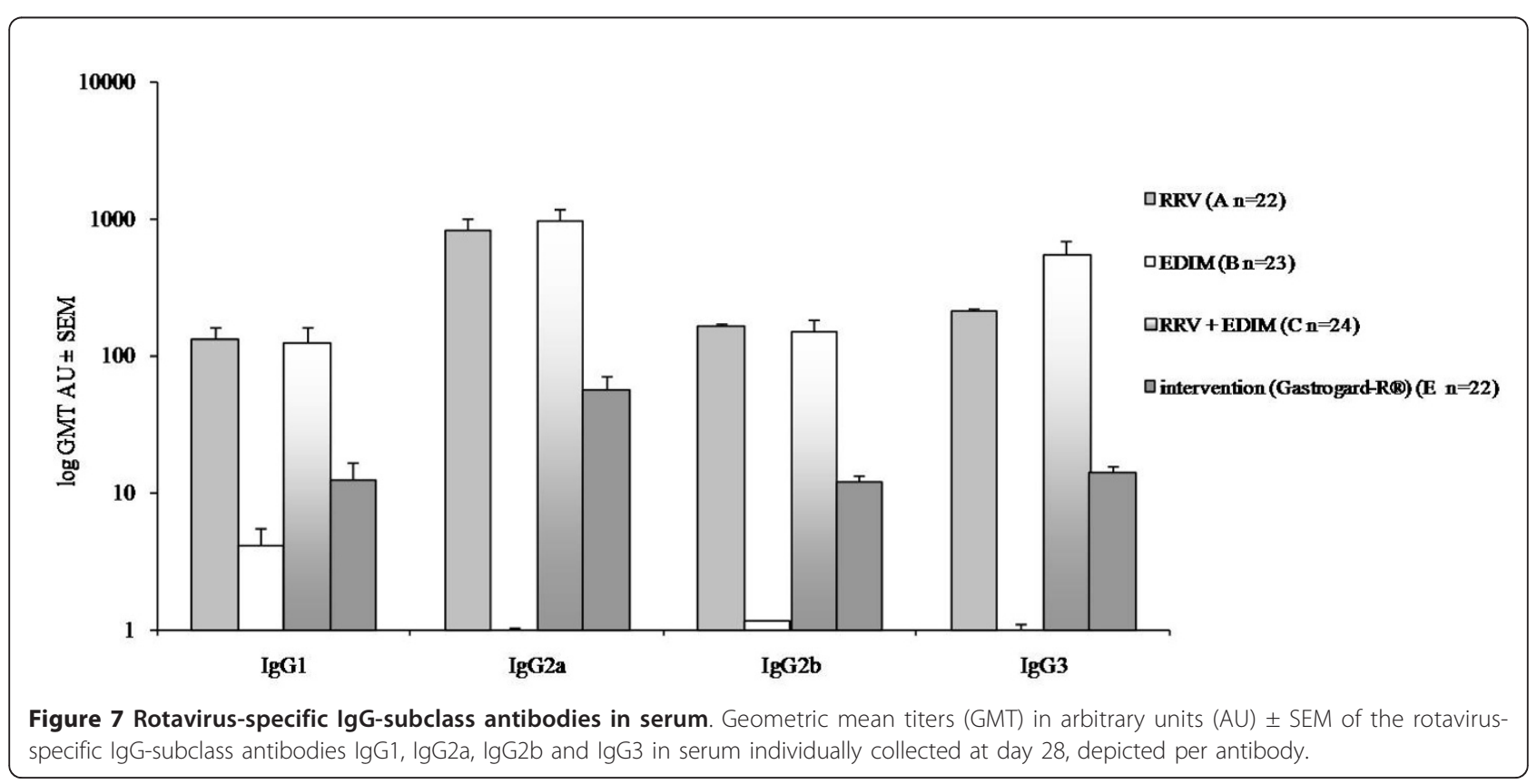


As for protection to rotavirus reinfection, B cells are absolutely necessary for long-term protection against rotavirus re-infection [7]. On the other hand, $\mathrm{T}$ cells are important for antiviral immunity in mice as well. CD $4^{+}$ $\mathrm{T}$ cells are essential for the development of more than $90 \%$ of the rotavirus-specific intestinal IgA and their presence seems to be critical for the establishment of protective long term memory responses [15]. Moreover, murine rotavirus-specific $\mathrm{CD} 8^{+} \mathrm{T}$ cells can mediate short-term partial protection against reinfection [19]. These data implicates that there is not one specific route that leads to rotavirus clearance and/or protection to rotavirus re-infection, but that both $\mathrm{B}$ cell as well as $\mathrm{T}$ cell-dependent and independent mechanisms can lead to clearance of infection and long-term maintenance of protection [20]. Within the model as described herein, both aspects of immune responses related towards protection can be studied.

Sheridan et al. was one of the first to describe a mouse model studying rotavirus-specific immunity [5]. Mice (CD-1) were infected orally with EDIM virus at 1,7 or 21 days of age. Severe disease was observed in animals infected at 1 day of age and lasted for at least 9 days. Disease was observed in mice infected at day 7 of age also, but was less severe and lasted only 5 days. Mice infected at 21 days of age did not show any evidence of clinical illness. These findings were comparable to our study where the mice were inoculated with RRV at day 7 of age and illness and diarrhea was seen for 5 days in approximately $70 \%$ of the animals. If the animals were supplemented with rotavirus-specific antibodies (Gastrogard- $\mathrm{R}^{\mathbb{B}}$ ) orally, the animals were protected completely from rotavirusinduced diarrhea. Inoculation of EDIM at day 17 of age did not result in any clinical symptoms and infection was measured by the analysis of rotavirus shedding in feces. Fecal viral shedding after a secondary EDIM inoculation showed that a primary rotavirus infection protected against viral shedding by $81 \%$ during a secondary inoculation. Administration of Gastrogard- $R^{\circledR}$, which completely protected the mice from diarrhea and illness during a primary infection, showed no protection during the secondary inoculation though the viral shedding seemed to disappear more rapidly compared to the group which received only EDIM without primary RRV inoculation.

Delayed-type hypersensitivity (DTH) is an important in vivo manifestation of cell-mediated immune responses. In our study, a rotavirus-specific DTH using EDIM was elicited at day 27 of age. In mice only inoculated with RRV at day 7, no DTH response was measurable compared to the control group. The mice receiving only EDIM at the age of 17 days however showed a significant DTH response to EDIM. This DTH disappeared in the mice which have been inoculated with both RRV and EDIM. Thus, not only adult mice that were re-infected after a primary infection showed a suppressed DTH as seen previously by Sheridan et al [5] but also mice who received the primary infection at a young age and a re-infection at an older age showed the same DTH suppression. Cellular responses to rotavirus were also analyzed by ex vivo restimulation of $\mathrm{T}$ cells isolated from the spleen with UVinactivated rotavirus. Inactivation by exposure to UV radiation destroys the integrity of rotavirus RNA and also removes the non-specific stimulatory effects of the virus when assayed on non-immune cells. A disadvantage of UV-inactivation over live virus is that inactivated virus has been shown to produce a lower level of proliferation than that induced by live virus [21]. In the present experiments, the proliferation level was low, although a significant increase in $\mathrm{T}$ cell proliferation was seen in the mice receiving both RRV and EDIM and also in the Gastrogard- $\mathrm{R}^{\mathbb{B}}$ group. In these mice, even though during a primary infection clinical illness was completely blocked, the immune system was activated.

$>$ Much controversy still exists as to whether serum antibodies against rotavirus are directly involved in protection or merely reflect recent infection, leaving the protective role to mucosal or cell-mediated immunity. Reviewed data from a variety of studies in humans suggest that serum antibodies, if present at critical levels, are either protective themselves or are an important and powerful correlate of protection against rotavirus disease [22]. Previous studies in infant mice, rabbits and humans have determined that rotavirus-specific IgM levels increase during the acute-phase of infection (before 7 days p.i.) and then decrease gradually. Therefore, rotavirus-specific IgM is seen as a marker of primary infection. Rotavirus-specific IgA and IgG levels were increased in the convalescent-phase of the infection $[5,23,24]$. Administration of RRV at day 7 resulted in the development of an antibody titer after 21 days, predominantly of the IgG2a subclass. Similar subclass restriction after virus infections was seen previously $[25,26]$. Administration of EDIM to previously RRV inoculated mice did not result in an increase of the antibody titer. Administration of EDIM at day 17 without a previous RRV inoculation resulted in normal levels of rotavirus-specific IgM and a small amount of rotavirusspecific IgG (subclass) antibodies, most likely due to the fact that 10 days p.i. is too early to measure the development of IgG antibodies. Intervention with Gastrogard$R^{\circledR}$ showed low antibody titers, but still significantly higher than the group who were inoculated with EDIM only, indicating that the rotavirus, although not able to induce diarrhea during the primary infection, could still provoke an antibody reaction.

Gastrogard- $R^{\circledR}$ is prepared from colostrum of hyperimmunised cows and contains high antibody titers against four human rotavirus serotypes, as measured in 
a virus neutralisation test [13]. The efficacy of passive immunization was established in calves which were immunized by subcutaneous injection of colostral whey with a high IgGl rotavirus antibody titer and challenged with virulent bovine rotavirus $48 \mathrm{~h}$ later. Calves were protected from rotavirus infection and diarrhea. Results further indicated that circulating IgG1 antibody appeared in the gastrointestinal tract of neonatal calves [27]. Previous research already showed that rotavirus antibody activity survived passage through the human gastrointestinal tract [28]. Gastrogard- $R^{\circledR}$ is used as prophylactic treatment of 'at risk' children aged one month to three years to prevent diarrhea due to rotavirus infection. The efficacy of treatment with Gastrogard- $R^{\circledR}$ was established in a clinical trial in children aged 3 to 15 months [13]. The in vitro inhibitory effect of Gastrogard- $R^{\circledR}$ was established in our laboratory in a rotavirus (RRV) titration assay using MA-104 cells (data not shown). In this assay Gastrogard- $R^{\circledR}$ was shown to have a strong inhibitory effect on the infectivity of rotavirus with an $\mathrm{IC}_{50}$ of $1 \mu \mathrm{g} / \mathrm{ml}$. Bovine milk and bovine milk constituents like lactadherin have been studied on their inhibitory activity in vitro and in in vivo rotavirus models [29]. Various compounds present in whey protein concentrate can ameliorate the severity and incidence of experimental rotaviral diarrhea and modulate the mucosal and systemic immune in suckling rats [30] and suckling mice [31]. However, none of these dairy compounds were able to completely inhibit clinical symptoms during a primary rotavirus infection, which is usually attended with the most severe clinical symptoms like diarrhea and vomiting [32].

\section{Conclusions}

In this study was found that oral administration of rotavirus antibodies can completely protect neonatal mice from clinical symptoms of illness during a primary rotavirus infection. Furthermore, an enhanced rotavirus-specific $\mathrm{T}$ cell proliferation and a small but detectable level of rotavirus-specific antibodies were found after re-infection suggesting improved $\mathrm{T}$ cell responses and a slight $\mathrm{B}$ cell response. Also shedding of rotavirus after EDIM inoculation seemed to disappear more rapidly in mice treated with rotavirus antibodies than in mice inoculated with EDIM alone. These results indicate that even though symptoms of a primary rotavirus infection were prevented, an activation of the immune system was still detectable. Preventing a primary infection by using Gastrogard- $R^{\circledR}$, activation of the immune system can still occur and could be helpful during re-infection knowing that both arms of the immune system play a pivotal role in immunity to rotavirus infection. These data show that this intervention model can be used for studying clinical symptoms as well as immune responses required for protection against viral re-infection.

\section{Abbreviations}

$\mathrm{CCID}_{50}$ : cell culture infective dose; Con A: Concanavalin A; DTH: delayed-type hypersensitivity; EDIM: epizootic-diarrhea infant-mouse; RRV: rhesus rotavirus; SA-11: simian rotavirus

\section{Acknowledgements}

The authors thank Wim Vos and Matthijs van Eck of the Dutch Vaccine Institute for their excellent technical assistance. Dr. Ward is thanked for his generous gifts of virus stocks and support for further development of this model.

\section{Author details}

${ }^{1}$ Danone Research Centre for Specialised Nutrition, P.O. Box 7005, 6700 CA Wageningen, The Netherlands. ${ }^{2}$ Cincinnati Children's Hospital Medical Center, Division of Infectious Diseases, 3333 Burnet Ave, Cincinnati, $\mathrm{OH}$ 45229 3039, USA. ${ }^{3}$ Former employee of Danone Research Centre for Specialised Nutrition, P.O. Box 7005, 6700 CA Wageningen, The Netherlands. ${ }^{4}$ Dutch Vaccine Institute, P.O. Box 457, 3720 AL Bilthoven, The Netherlands. ${ }^{5}$ Utrecht Institute for Pharmaceutical Sciences, P.O. Box 80115, 3508 TC Utrecht, The Netherlands.

\section{Authors' contributions}

KK participated in the design and coordination of the in vivo study, participated in the in vitro experiments and drafted the manuscript. MM participated in the design in vivo study and helped to draft the manuscript. AC participated in execution and analysis of the in vitro experiments. GVA participated in the design of the in vivo study and was responsible for the execution of the in vivo study. JG has been involved in drafting the manuscript for important intellectual content and has given final approval for the manuscript to be submitted. BvtL participated in the design of the in vivo study and helped to draft the manuscript. All authors read and approved the final manuscript.

\section{Competing interests}

The authors declare that they have no competing interests.

Received: 26 January 2011 Accepted: 8 March 2011

Published: 8 March 2011

\section{References}

1. Dennehy PH: Rotavirus vaccines: an overview. Clin Microbiol Rev 2008, 21:198-208.

2. Murphy TV, Gargiullo PM, Massoudi MS, Nelson DB, Jumaan AO, Okoro CA, Zanardi LR, Setia S, Fair E, LeBaron CW, et al: Intussusception among infants given an oral rotavirus vaccine. N Engl J Med 2001, 344:564-572.

3. Franco MA, Angel J, Greenberg HB: Immunity and correlates of protection for rotavirus vaccines. Vaccine 2006, 24:2718-2731.

4. Kapikian AZ, Hoshino Y, Chanock RM: Rotaviruses. Fields Virology 2001, 2:1806.

5. Sheridan JF, Eydelloth RS, Vonderfecht SL, Aurelian L: Virus-specific immunity in neonatal and adult mouse rotavirus infection. Infect Immun 1983, 39:917-927.

6. Ward RL: Possible mechanisms of protection elicited by candidate rotavirus vaccines as determined with the adult mouse model. Viral Immunol 2003, 16:17-24.

7. Franco MA, Greenberg HB: Role of B cells and cytotoxic T lymphocytes in clearance of and immunity to rotavirus infection in mice. J Virol 1995, 69:7800-7806.

8. Feng N, Burns JW, Bracy L, Greenberg HB: Comparison of mucosal and systemic humoral immune responses and subsequent protection in mice orally inoculated with a homologous or a heterologous rotavirus. J Virol 1994, 68:7766-7773.

9. McNeal MM, Rae MN, Ward RL: Evidence that resolution of rotavirus infection in mice is due to both CD4 and CD8 cell-dependent activities. J Virol 1997, 71:8735-8742. 
10. Franco MA, Tin C, Greenberg HB: CD8+ T cells can mediate almost complete short-term and partial long-term immunity to rotavirus in mice. J Virol 1997, 71:4165-4170.

11. Jaimes MC, Feng N, Greenberg HB: Characterization of homologous and heterologous rotavirus-specific T-cell responses in infant and adult mice. $J$ Virol 2005, 79:4568-4579.

12. VanCott JL, Prada AE, McNeal MM, Stone SC, Basu M, Huffer B Jr, Smiley KL, Shao M, Bean JA, Clements JD, et al: Mice develop effective but delayed protective immune responses when immunized as neonates either intranasally with nonliving VP6/LT(R192G) or orally with live rhesus rotavirus vaccine candidates. J Virol 2006, 80:4949-4961.

13. Davidson GP, Whyte PB, Daniels E, Franklin K, Nunan H, McCloud PI, Moore AG, Moore DJ: Passive immunisation of children with bovine colostrum containing antibodies to human rotavirus. Lancet 1989, 2:709-712

14. Adkins B, Leclerc C, Marshall-Clarke S: Neonatal adaptive immunity comes of age. Nat Rev Immunol 2004, 4:553-564.

15. Franco MA, Greenberg HB: Immunity to rotavirus in T cell deficient mice. Virology 1997, 238:169-179.

16. Blutt $\mathrm{SE}$, Warfield $\mathrm{KL}$, Lewis $\mathrm{DE}$, Conner ME: Early response to rotavirus infection involves massive B cell activation. J Immunol 2002. 168:5716-5721.

17. Dharakul T, Rott $L$, Greenberg HB: Recovery from chronic rotavirus infection in mice with severe combined immunodeficiency: virus clearance mediated by adoptive transfer of immune CD8+ T lymphocytes. J Virol 1990, 64:4375-4382

18. McNeal MM, Barone KS, Rae MN, Ward RL: Effector functions of antibody and CD8+ cells in resolution of rotavirus infection and protection against reinfection in mice. Virology 1995, 214:387-397.

19. Franco MA, Greenberg HB: Immunity to rotavirus infection in mice. J Infect Dis 1999, 179(Suppl 3):S466-469.

20. Blutt SE, Warfield KL, Estes MK, Conner ME: Differential requirements for T cells in viruslike particle- and rotavirus-induced protective immunity. $J$ Virol 2008, 82:3135-3138

21. Bruce MG, Campbell I, Xiong Y, Redmond M, Snodgrass DR: Recognition of rotavirus antigens by mouse L3T4-positive T helper cells. J Gen Virol 1994, 75(Pt 8):1859-1866

22. Jiang B, Gentsch JR, Glass Rl: The role of serum antibodies in the protection against rotavirus disease: an overview. Clin Infect Dis 2002, 34:1351-1361.

23. Davidson GP, Hogg RJ, Kirubakaran CP: Serum and intestinal immune response to rotavirus enteritis in children. Infect Immun 1983, 40:447-452.

24. Conner ME, Gilger MA, Estes MK, Graham DY: Serologic and mucosal immune response to rotavirus infection in the rabbit model. J Virol 1991, 65:2562-2571.

25. Coutelier JP, van der Logt JT, Heessen FW, Warnier G, Van Snick J: IgG2a restriction of murine antibodies elicited by viral infections. J Exp Med 1987, 165:64-69.

26. Coutelier JP, van der Logt JT, Heessen FW, Vink A, van Snick J: Virally induced modulation of murine lgG antibody subclasses. J Exp Med 1988, 168:2373-2378.

27. Besser TE, Gay CC, McGuire TC, Evermann JF: Passive immunity to bovine rotavirus infection associated with transfer of serum antibody into the intestinal lumen. J Virol 1988, 62:2238-2242.

28. Pacyna J, Siwek K, Terry SJ, Roberton ES, Johnson RB, Davidson GP: Survival of rotavirus antibody activity derived from bovine colostrum after passage through the human gastrointestinal tract. J Pediatr Gastroenterol Nutr 2001, 32:162-167.

29. Kvistgaard AS, Pallesen LT, Arias CF, Lopez S, Petersen TE, Heegaard CW, Rasmussen JT: Inhibitory effects of human and bovine milk constituents on rotavirus infections. J Dairy Sci 2004, 87:4088-4096.

30. Perez-Cano FJ, Marin-Gallen S, Castell M, Rodriguez-Palmero M, Rivero M, Castellote C, Franch A: Supplementing suckling rats with whey protein concentrate modulates the immune response and ameliorates rat rotavirus-induced diarrhea. J Nutr 2008, 138:2392-2398.

31. Wolber FM, Broomfield AM, Fray L, Cross ML, Dey D: Supplemental dietary whey protein concentrate reduces rotavirus-induced disease symptoms in suckling mice. J Nutr 2005, 135:1470-1474.

32. Mrukowicz JZ, Thompson J, Reed GW, Tollefson SJ, Kobayashi M, Araki K, Wright PF: Epidemiology of rotavirus in infants and protection against symptomatic illness afforded by primary infection and vaccination. Vaccine 1999, 17:745-753.

doi:10.1186/1743-422X-8-109

Cite this article as: Knipping et al:: A gastrointestinal rotavirus infection mouse model for immune modulation studies. Virology Journal 2011 8:109.

\section{Submit your next manuscript to BioMed Central and take full advantage of:}

- Convenient online submission

- Thorough peer review

- No space constraints or color figure charges

- Immediate publication on acceptance

- Inclusion in PubMed, CAS, Scopus and Google Scholar

- Research which is freely available for redistribution 